\title{
AS METÁFORAS EM ANÚNCIOS PUBLICITÁRIOS: UMA ANÁLISE ATRAVÉS DA LINGUÍSTICA COGNITIVA
}

\author{
Ana Cristina Oliveira Santos \\ Lucas Santos Campos
}

RESUMO: A sociedade está cercada por anúncios publicitários, veiculados através da TV, de revistas, jornais, da internet e outros meios de comunicação social. É comum o emprego de figuras de pensamento nesses anúncios, principalmente da metáfora. Esse fato nos motivou a realizar análise, de algumas dessas figuras, empregadas em comerciais que envolvem bebidas e produtos de limpeza. A Linguística Cognitiva dispõe de algumas teorias referentes à abordagem de metáforas, sendo assim, foi conveniente optar por uma delas para servir de suporte para a análise das propagandas selecionadas para este aporte. Elegemos, então a Teoria da Integração de Fauconnier e Turner. A propaganda é um veículo que exerce uma grande influência sobre as pessoas, seduzindo-as com suas imagens e enunciados criativos, a fim de persuadir o consumidor, que muitas vezes é "enlaçado" pelas cores, palavras e imagens metafóricas, e, em muitas circunstâncias, as pessoas agem, movidas pela compulsão e acabam, eventualmente, adquirindo bens sem que tenham uma real necessidade deles. Assim, apontamos algumas pistas que possam auxiliar as pessoas no processo de análise de anúncios comerciais, o que pode favorecê-las no processo de suas escolhas, em meio ao poder de sedução das propagandas.

PALAVRAS-CHAVE: Linguística Cognitiva; Metáfora; Propaganda.

\section{Introdução}

A metáfora é conhecida pela maioria das pessoas como uma figura de linguagem que geralmente se estuda no apêndice das gramáticas normativas. O que é transmitido nas aulas de Língua Portuguesa é simplesmente a metáfora, presente em poemas e textos literários em prosa, com isso, o conceito fica atrelado à simplificação de apenas um recurso 
estilístico e incrementador textual. Contudo, ao realizar leituras sobre metáfora, na perspectiva da Linguística Cognitiva, percebemos que a ocorrência dessa figura se dá de forma espontânea, sem que os falantes planejem sua estruturação nas expressões metafóricas.

O uso das metáforas pelos falantes se dá, regra geral, de forma inconsciente. Esse recurso está presente na nossa oralidade, no dia a dia. Ao atentarmos para os diálogos mais comuns do cotidiano, percebemos que a espontaneidade da linguagem abstrata e metafórica sempre está em destaque, a fim de que tanto as representações emocionais, quanto o processo de interação ocorram de forma eficiente.

Para Lakkof (1999) a essência da metáfora está em entender e experienciar um tipo de coisa em termo de outra. Podemos ilustrar essa premissa, a partir do seguinte exemplo: quando alguém está exausto e afirma isso de forma denotativa "Hoje estou cansado", é diferente de quando se aplica o uso metafórico “hoje estou moído”, “quebrado”. Portanto, as metáforas são úteis para facilitar o entendimento abstrato. Ela intensifica o emocional que o falante deseja expressar e também atinge o interlocutor nesse particular.

Apresentamos a metáfora como a Linguística Cognitiva explica, como um fenômeno linguístico presente em todas as línguas humanas. De forma sintética abordamos alguns conceitos teóricos, no intuito de compreender a metáfora não sob a ótica gramatical, que a define como uma simples figura, mas como um elemento cognitivo que faz parte do ser humano.

Em seguida, abordamos algumas explicações de conceitos essenciais ligados à metáfora, à luz da Linguística Cognitiva, apresentamos alguns anúncios publicitários que possuem a presença da metáfora, tanto em seus enunciados escritos, como também em suas imagens metafóricas. Através da Teoria da Integração de Fauconnier e Turner é que analisaremos três propagandas, sendo que a primeira é anúncio de bebida, a segunda é de comida e a terceira de material de limpeza.

A grande criatividade na produção de anúncios publicitários, abrangendo as imagens, cores, enunciados escritos, construções metafóricas podem levar o consumidor a fazer sua opção de compra ou não compra, assim como optar por essa ou aquela marca, 
guiado pelo poder de sedução/persuasão que a propaganda possa exercer sobre ele. Em muitos casos, o indivíduo não necessita adquirir determinado produto, contudo o poder da atração que as propagandas proporcionam conseguem levar o consumidor à compra. Este estudo pretende conduzir o leitor à reflexão sobre a consciência nas escolhas diante de tantas ofertas através dos anúncios publicitários.

O texto está apresentado com tópicos que apresentam os aspectos relevantes da Linguística Cognitiva, no que diz respeito à Metáfora, assim como imagens de anúncios publicitários e os diagramas para as análises.

Abordamos, a seguir, os chamados frames, fator muito importante para a compreensão da metáfora à luz da Linguística Cognitiva.

\section{Frames}

Ao pé da letra, frame corresponde a um "quadro", "armação"; concretamente, a um porta-retrato. Teoricamente, a Linguística Cognitiva vai tratar dos frames como construtos da nossa imaginação. Kövecses (2006, p. 69) afirma que Frames são construtos da nossa imaginação e não representações mentais que se encaixam diretamente em uma realidade objetiva preexistente. Resumindo, frames são dispositivos imaginativos da mente.

Todos os conceitos semânticos que adquirimos, não dependem só da questão puramente cognitiva, mas também dependem muito dos aspectos culturais pelos quais o indivíduo está inserido. Podemos afirmar que o conjunto de elementos que compõem um frame não está fechado em si, incluindo, portanto, dados da experiência individual.

Ao tratar da semântica dos itens lexicais e construções gramaticais, Charles Fillmore (1985) argumenta a respeito do frame, indicando que se trata de um sistema estruturado de conhecimento armazenado na memória de longo prazo e organizado a partir das experiências individuais. Ele prossegue com sua explicação de que o significado ou interpretação de uma palavra depende do acesso de estruturas de conhecimento que relacionam os elementos e entidades associadas a cenas da experiência humana; ou seja, todo o domínio semântico é dependente de um conhecimento prévio, de experiências preexistentes 
Retomando o conceito de Kövecses (2006) sobre frame, como construtos da nossa própria imaginação, veremos alguns exemplos que podem ilustrar tal afirmação. Quando falamos na festa de São João, por exemplo, imediatamente associamos a essa palavra ideias ligadas ao seu significado, como: festa do mês de junho, fogueira, foguetes, dança, quadrilha, bandeirolas, comidas típicas como a pamonha, o milho, biscoitos, bolos e as tradicionais bebidas como quentão, cachaça etc. Dessa forma, um indivíduo que não tem o conhecimento sobre festa junina, não tem experiência com este aspecto cultural brasileiro, certamente, não fará essas associações citadas.

Ferrari (2011) tece ainda sobre frame a seguinte afirmação:

A interpretação de uma determinada palavra, ou de um conjunto de palavras, requer o acesso a estruturas de conhecimento que relacionam elementos e entidades associados a cenas da experiência humana, considerando-se as bases físicas e culturais dessa experiência. (FERRARI, 2011, p. 50).

O conjunto de tudo isso, grosso modo, constitui um frame. Sobre frame, veremos um último exemplo: se pensarmos na palavra manga, podemos associá-la imediatamente a uma fruta, porém, podemos também lembrar da manga de camisa. Por essa razão os frames também estão relacionados às questões culturais e linguísticas, em que o indivíduo está inserido ou o contexto a que ele pertença.

Podemos concluir que a apropriação das metáforas, pelos falantes está intimamente ligada à questão do frame, uma vez que a influência cultural e linguística também está imbricada na realização do fenômeno cognitivo da metáfora. Diante dessa explanação, é conveniente tal afirmação de que frame e metáfora são dois elos que juntos definem a compreensão das expressões metafóricas.

Nesta questão de frame, podemos indicar que, na prática da interpretação de metáforas por crianças há momentos em que a criança não compreende expressões metafóricas do cotidiano, assim interpreta a expressão com o sentido denotativo. Com o passar do 
tempo, a criança vai compreendendo as metáforas, conforme o meio em que ela está inserida; portanto, os frames que a criança vai recebendo e absorvendo, ao longo da sua vida, é que repercutirão na compreensão das expressões metafóricas.

Este exemplo da aquisição e compreensão de expressões metafóricas do cotidiano pela criança, evidencia este elo entre frame e metáfora. Quando a criança não compreende um tipo de metáfora, significa que, quando o frame foi acionado, não houve interpretação, visto que a experiência ainda não foi adquirida para compreender a expressão ouvida.

\section{Metáfora}

Há muito tempo que se estuda metáfora como uma figura de linguagem, a partir de uma visão clássica e retórica. Todavia, ao nos debruçarmos nos estudos teóricos da Linguística Cognitiva, podemos ampliar os conceitos de metáfora, de modo que chegamos à conclusão de que estes conceitos, particularmente a partir dos estudos de Lakkof e Johnson, vão além do que os livros didáticos utilizados nas aulas de Língua Portuguesa dos cursos Fundamental e Médio propõem. Lakkof e Johnson (2002) apresentam o conceito de metáfora nos seguintes termos:

A metáfora é, para a maioria das pessoas, um recurso da imaginação poética e um ornamento retórico; é mais uma questão de linguagem extraordinária do que de linguagem ordinária [...]. Nós descobrimos, ao contrário, que a metáfora está infiltrada na vida cotidiana, não somente na linguagem, mas também no pensamento e na ação. Nosso sistema conceptual ordinário, em termos do qual não só pensamos, mas também agimos, é fundamentalmente metafórico por natureza. (LAKKOF E JOHNSON, 2002, P. 45).

A nossa linguagem do cotidiano está cercada de usos de metáfora, sem que haja um planejamento prévio para tais estruturações. Quando estamos dialogando em conversas informais e também em contextos formais, as expressões metafóricas são evidentes em nossos discursos, de forma natural e espontânea, visto que, nosso sistema conceptual é fundamentalmente metafórico. A metáfora faz parte de todas as línguas humanas. 
No próximo tópico trazemos uma breve explanação sobre as metáforas primárias e conceptuais, que são aspectos básicos para compreendermos este fenômeno cognitivo presente na nossa linguagem.

\section{Metáforas primárias e conceptuais}

Para Lakoff e Johnson (2002), o nosso sistema conceptual é fundamentalmente metafórico. Dessa forma, as metáforas não se encontram na linguagem, mas sim no pensamento inconsciente. O papel da linguagem é apenas o de explicitar essas metáforas conceptuais através de "expressões metafóricas". Portanto, para estes autores, as metáforas são figuras do pensamento, visto que a origem é na mente e não na língua.

O conceito de metáfora, segundo os autores deixa absolutamente claro que a apropriação de metáforas pelos falantes se dá a partir de uma perspectiva cognitiva, algo inconsciente aos indivíduos. É claro, portanto, que nós não premeditamos, não formulamos metáforas para inseri-las num contexto dialógico. Quando menos percebemos, já expressamos metáforas em nossos diálogos cotidianos. Se fizermos uma observação minuciosa em diálogos do dia a dia, percebemos a naturalidade pela qual funciona esse fenômeno linguístico, que é a metáfora.

As metáforas consideradas primárias, podem ser explicadas a partir da questão da proximidade física, aqueles primeiros momentos de afeto entre o bebê e sua mãe, o aquecimento do abraço, do aconchego de fato. Johnson (1999) afirma que intimidade psicológica é proximidade física; ou seja, as nossas experiências físicas e psicológicas desde o nosso nascimento vão implicar nesse tipo de metáfora denominada metáfora primária. Podemos citar um exemplo bastante comum no nosso dia a dia como: "aquele homem é frio com a gente", "meu pai é muito distante dos filhos", "temos parentes muito próximos a nós". Questões que envolvem proximidade e distância de relacionamentos entre seres humanos, sejam "frios” ou "quentes", estão ligados a metáforas primárias que também acontecem de modo automático, inconsciente. 
O afeto, neste caso, está intimamente ligado ao calor, que também indica proximidade afetiva. A frieza, ao contrário, está relacionada à distância, à falta de afetividade em relacionamentos pessoais. Podemos explicar melhor, partindo do momento em que o ser humano nasce; logo que a mãe afaga o bebê, aquece em seu peito, amamenta, aquece o frio; essas ações que ligam a mãe ao filho, numa expressão de "calor humano", fazem com que o indivíduo, ao longo da vida, tenha uma associação do afeto recebido ao nascer, a outras situações. O contexto de carinho, aproximação, proteção etc., remetem a calor; por outro lado, as situações de indiferenças, distâncias etc., pelo contrário, remetem à frieza. Essas são metáforas primárias que podemos compreender, a partir desse princípio afetivo que ocorre no início da vida humana.

Segundo Lakkof e Johnson (2002, p. 8) a metáfora é para a maioria das pessoas um dispositivo da imaginação poética. Contudo, a metáfora não é simplesmente uma característica da linguagem, ela está intimamente ligada ao pensamento e ação. Em nossa vida cotidiana, estamos cercados da presença da metáfora. Até nos mínimos detalhes, a forma de como nos relacionamos com o outro, dentro da nossa realidade, o que sentimos, o que pensamos, vivenciamos com a metáfora. Uma vez que a comunicação é baseada no mesmo sistema conceptual que usamos no pensar e agir, a linguagem é uma fonte importante de evidência para que percebamos a metáfora como um mecanismo automático em todas as línguas.

Na nossa linguagem cotidiana a apropriação da metáfora em diversas situações em que se emitem expressões. Ex.: "Argumento é guerra", "ele atacou todos os pontos fracos em meus argumentos", "ele demoliu seu argumento", "suas críticas foram direto ao alvo", "se você usar essa estratégia, ele vai acabar com você". Diante dessas expressões, muitas das coisas que fazemos na discussão são parcialmente estruturadas pelo conceito de guerra.

Embora não haja nenhuma batalha física, há uma batalha verbal, e a estrutura de um argumento de ataque, defesa, contra-ataque etc. reflete isso. É neste sentido que uma relação, uma demanda, um debate, ganha status de guerra. 
No que diz respeito à sistematicidade dos conceitos metafóricos, Lakkof e Johnson (2002, p. 11) afirmam que as expressões metafóricas em nossa língua estão ligadas a conceitos metafóricos de uma forma sistemática. Para termos melhor ideia de como as expressões metafóricas estão presentes em todos os dias em nossa linguagem, podemos dar uma visão dos conceitos que estruturam nossas atividades cotidianas. Vamos considerar os seguintes exemplos: “tempo é dinheiro", "estou desperdiçando o meu tempo”, “estou investindo muito tempo nela", "estou correndo contra o tempo", "você tem tempo de sobra", "usar seu tempo de forma lucrativa" "perdi muito tempo", "obrigada pelo seu tempo" etc..

Em relação a essas expressões relacionadas ao tempo, podemos observar que na nossa cultura o tempo é uma "mercadoria valiosa", em função da maneira com que o conceito de trabalho desenvolveu-se na era moderna, na cultura ocidental, onde o trabalho é normalmente associado ao tempo que se gasta. Assim, o tempo é precisamente quantificado. Em virtude disso, tornou-se costumeiro pagar pessoas por hora, semana, quinzenalmente e mensalmente. Em nossa cultura, "tempo é dinheiro", em diversas modalidades: unidades de mensagem de telefone, salários por hora, quarto de hotel, taxas de orçamento anual, juros de empréstimos, etc..

Essas práticas são relativamente novas na história da humanidade, e não significa dizer que elas existam em todas as culturas. Elas surgiram nas sociedades industrializadas modernas e estruturam nossas atividades básicas de uma maneira mais profunda. Isso corresponde ao fato de que o tempo é um recurso valioso.

Assim, encaramos o tempo como o tipo de coisa que pode ser gasto, desperdiçado, economizado, de modo que valha a pena o investir. "Tempo é dinheiro", "tempo é um recurso limitado", e "o tempo é uma mercadoria valiosa” todas essas expressões, são conceitos metafóricos em função de estarmos usando nossas experiências diárias com o dinheiro, que é para todos nós, um recurso altamente valioso para a manuntenção da vida em sociedade. 
Esses exemplos de expressões metafóricas representam ilustrações que comprovam ser a metáfora um mecanismo que envolve a conceptualização de um domínio de experiência em termo de outro. Para cada metáfora identificamos o "domínio-fonte” e o “domínio-alvo". O domínio-fonte corresponde a propriedades físicas, enquanto o domínio-alvo tende a ser mais abstrato

Se dizemos, por exemplo: "Carro mil é uma tartaruga". Estamos diante de um domínio fonte: tartaruga e todos os conceitos atrelados a ela, como lentidão, por exemplo. A escolha por um desses conceitos está diretamente ligada ao contexto no qual o enunciado apareceu. É o contexto que circunscreve a ação da metáfora. Entendemos, portanto, que o uso da metáfora, em vez de dizer diretamente que o carro mil é lento, é uma forma de dar uma sutileza de comparação ao que se diz, contudo implica que o interlocutor esteja apto a perceber o sentido dado naquele momento. Caso contrário, a metáfora continuará a existir naquele enunciado, mas, ao não ser percebida, poderá comprometer a geração de sentido.

Outro exemplo de metáfora bem presente na sociedade brasileira, ainda abordando aspectos de "domínio-fonte" e "domínio-alvo", é a metáfora "comer", no que diz respeito ao sexo. É como se o sexo fosse um alimento, ou o próprio ser humano homem e mulher fossem alimentos. No nosso cotidiano podemos ouvir pessoas empregarem o verbo "comer" se referindo à relação sexual. Exemplo: “Ontem à noite, eu comi a irmã do meu melhor amigo". Analisando sob os aspectos domínio-fonte e domínio-alvo podemos afirmar que: (1) Frame de alimento (domínio-fonte) frame de sexo (Domínio-alvo); (2) Pessoa que se alimenta $\rightarrow$ parte "ativa" do ato sexual; (3) Ato de alimentar-se $\rightarrow$ manter relação sexual; (4) Alimento $\rightarrow$ parte "passiva" do ato sexual.

Vale ressaltar que, em nossa cultura, o machismo é uma característica, infelizmente, ainda presente, embora muitas vezes seja demonstrada de forma sutil. Nestas expressões relacionadas ao sexo, observamos que a figura feminina é apresentada de maneira passiva, 
ou seja, ela é representada como o "alimento". O homem é o que sempre "come”. Dificilmente uma mulher utiliza a expressão metafórica que "comeu" um homem. O comum é se ouvir que o homem "comeu" a mulher.

Assim, emerge o papel masculino de "comedor" em nossa cultura e o item lexical "comer" evoca a cena de alimentação com alguns dos seus padrões inferenciais: "comer a”, ou seja, um “agente a” (o sujeito) que come um “objeto b” (mulheres). É, contudo, a força de convenção da metáfora conceptual "sexo é alimento" em nossa cultura. A mulher se perpetua como um objeto, como uma comida que supre a necessidade do homem. Entretanto, não se pode excluir a possibilidade da existência da metáfora “comer", associada da mulher para o homem. A mulher de hoje também tem a autonomia de tratar o homem como seu "alimento", (metaforicamente), seu suprimento sexual. Embora a visão machista consista que o homem é quem "come” a mulher. Na realidade, essa metáfora se refere a ambos, no contexto semântico.

Apreciemos, a seguir, uma propaganda publicitária que se apropria da metáfora e, além disso, expressa o conteúdo sexual, apresentando a ambiguidade semântica e, como retratamos acima, expressando a metáfora conceptual "sexo é alimento", pela qual, mais uma vez, a mulher é retratada como alimento.

Figura 1 - Propaganda da cerveja Crystal

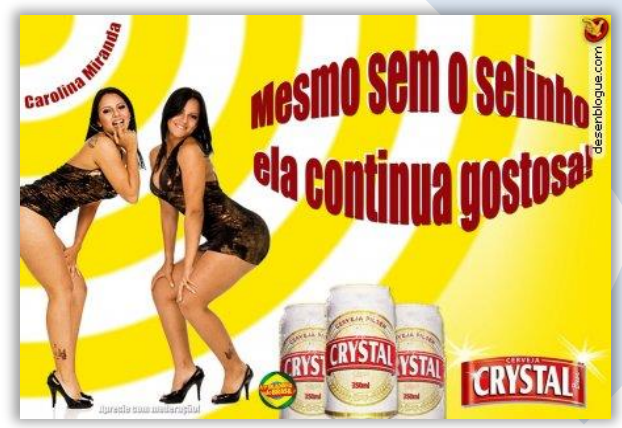

Disponível em: <https://www.google.com.br/search?biw=1366\&bih= 662\&tbm $=$ isch\&sa=1\&ei=NKQpW7f9L8XCwAS937A > Acesso em: 15 abr. 2018. 
Vemos claramente a ambiguidade no enunciado da cerveja que atribui o adjetivo "gostosa" à cerveja, entretanto, um outro objetivo do anúncio é, de fato, usar a figura da mulher como símbolo sexual e o adjetivo "gostosa" referente à mulher, evidencia a metáfora conceptual "sexo é alimento", uma vez que esse termo também está relacionado à alimentação, na medida em que um alimento pode ser qualificado como gostoso ou não.

A partir dos estudos de Lakoff e Johnson (1980) não é mais conveniente afirmar que a metáfora seja um mero recurso estilístico que embeleza a linguagem, mas, sim, a forma como categorizarmos o mundo à nossa volta, visto que ela nos possibilita compreender um aspecto de um conceito em termos de outro.

As construções que resultam dessas projeções seletivas entre domínios distintos nos permitem compreender a metáfora como produto das intrincadas relações biológicas, sociais, históricas e culturais, que os indivíduos vivenciam diariamente. Dessa maneira, podemos afirmar que nossa experiência com o mundo é de extrema importância para os processos de construção dos sentidos. Isso implica no que já discorremos a respeito dos frames também; a experiência humana implica de forma essencial.

\section{Metáfora de Coerência Cultural}

Conforme já referenciado anteriormente, o fenômeno da metáfora acontece num conjunto de aspectos, pelos quais estão inseridos: o cognitivo e a cultura pela qual o sujeito faz parte. Segundo Lakkof e Johnson (2003, p. 23) "os valores fundamentais em uma cultura serão coerentes com a estrutura metafórica dos seus próprios conceitos". Vejamos alguns exemplos: (1) "Mais é melhor" é coerente com "mais está acima e bom está acima", menos é melhor" não é coerente; (2) "Maior é melhor" é coerente com mais está acima e bem está acima". "Menor é melhor" não é coerente com eles; (3) "O futuro será melhor" é coerente com o futuro está acima e bom está acima. O futuro será pior não é coerente. "Haverá mais no futuro" é coerente com mais é acima e o futuro é acima.

Estes valores são profundamente ancorados em nossa cultura. "O futuro será melhor" é uma declaração de um conceito de progresso. "Haverá mais no futuro". A coerência 
cultural permite afirmar que o futuro sempre reserva coisas boas, ou seja, nunca se atribui uma questão negativa em relação ao futuro, uma vez que as perspectivas, no geral, de uma cultura, sempre são de melhorias.

Existem culturas em que o equilíbrio ou a centralidade desempenham um papel muito mais importante do que na nossa cultura. Consideremos a orientação não-espacial ativa-passiva. Para nós, "ativo" é para cima e "passivo" é abaixo, na maioria dos contextos. Contudo, há culturas onde a passividade é valorizada mais do que a atividade. Em geral, as principais orientações de cima para baixo, central-periférica, ativo-passivo, etc., parecem cortar todas as culturas, no entanto, quais conceitos são orientados e de que maneira são, variam de acordo a cada cultura.

Nesse sentido, Lakkof e Johnson (2002) afirmam que nossos pensamentos e ações são regidos por metáforas e que estas são uma forma de compreender o mundo, a nossa cultura e a nós mesmos. Estes valores são individuais, culturais e podem interferir nos conceitos metafóricos e nas expressões metafóricas que estamos sempre construindo em nossos diálogos e comunicações, de sorte que o resultado seria a obtenção de diferentes significados.

A seguir apresentamos a explicação sobre a Teoria da Integração de Fauconnier e Turner (1999) é a base para a análise de metáforas em anúncios publicitários neste trabalho.

\section{Teoria da Integração de Fauconnier e Turner}

O fenômeno-chave, responsável pelo fato de que não apenas reproduzimos os mundos simbólicos já existentes, mas, ao contrário, também produzimos novidades, é a mesclagem: "Ela [a mesclagem] consiste em integrar estruturas parciais de dois domínios separados em uma única estrutura com propriedades emergentes dentro de um terceiro domínio". (FAUCONNIER 1999, p.22).

O ponto crucial é que na teoria da Mesclagem, ao contrário de Lakoff \& Johnson, os dois espaços input trazem sua própria estrutura ao espaço em que ocorre a mescla, o que rompe com a tese da unidirecionalidade. No seu livro Mappings in Thought and Language, de 
1999, Fauconnier observa explicitamente, pela primeira vez, o fenômeno da metáfora como subcaso da Mesclagem, dirigindo sua atenção à discordância entre os dois espaços imput. Partindo do exemplo, “cavar seu próprio túmulo", Fauconnier (1999) mostra como inferências do domínio fonte são violadas na mesclagem, a despeito da tese da invariância estabelecida por Lakoff (1995): a estrutura causal é invertida por ações tolas que causam falhas, embora cavar um túmulo não cause morte. A estrutura intencional também não coincide, pois ninguém cava um túmulo inconscientemente.

Como consequência, a mesclagem cria uma estrutura emergente, por herdar de um domínio a estrutura concreta de túmulos, cavar e enterro, e por herdar do outro domínio as estruturas causal, intencional e do evento interno. É este o fenômeno que os autores denominam 'compressões', que surge logo que topologias de espaços distintos se chocam, contribuindo para o surgimento de algo novo, pois a partir de processos de compressão e descompressão, na mesclagem, são criadas situações contrafactuais nas relações temporais, espaciais ou de identidade.

Conforme a Integração Conceitual de Turner (2003) existe um mapeamento interespacial parcial que liga algumas contrapartes aos espaços mentais de entrada (inputs). Existe um espaço mental genérico que mapeia em cada uma das entradas e contém o que as entradas (inputs) têm em comum. Há um quarto espaço mental que é chamado de mescla (blending). Existe uma projeção seletiva das entradas para a mescla. É a partir desse esquema de diagramação que Turner propõe, que nos apropriaremos neste trabalho, a fim de esquematizar as análises das expressões metafóricas nos anúncios publicitários selecionados.

Vejamos a diagramação que representa os imputs e o espaço genérico: 
Figura 2 - Diagrama de Fauconnier e Turner

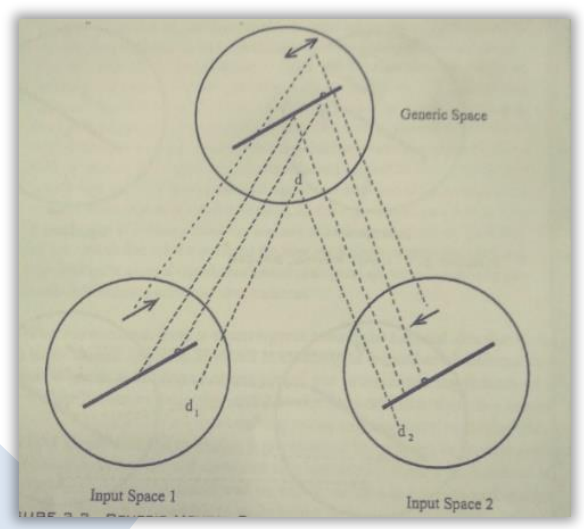

Fonte: Fauconnier e Turner (2003, p. 42)

A essência da Teoria da Integração Conceitual é a construção de uma correspondência parcial entre dois espaços de entrada (inputs) para projetar seletivamente elementos daquelas entradas em um quarto espaço mental que é o espaço integrado. (Blended space). A partir desse pressuposto, vejamos a seguir a configuração do diagrama que representa os inputs, o espaço genérico e o espaço da mescla ou "mesclagem".

Figura 3 - Diagrama da Teoria da Integração

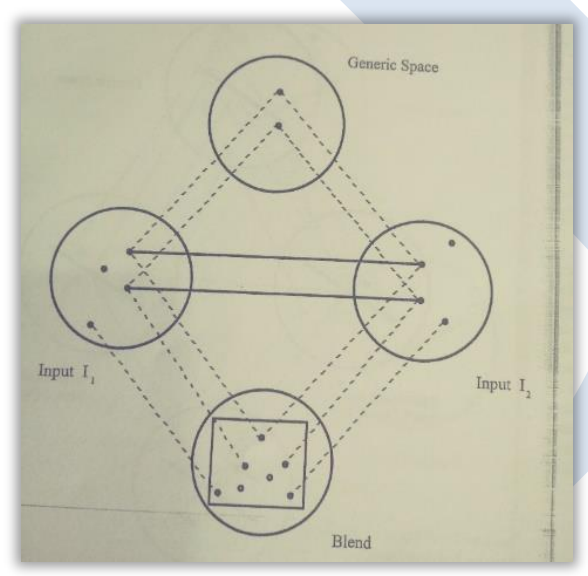

Fonte: Fauconnier e Turner (2003, p. 46) 
Este diagrama apresenta os nomes em Língua Inglesa, input, Generic Space e Blend.

A seguir a presentaremos um diagrama que representa os diagramas das análises de metáfora, em Língua Portuguesa:

Figura4 - Diagrama da Teoria da Integração em Língua Portuguesa.

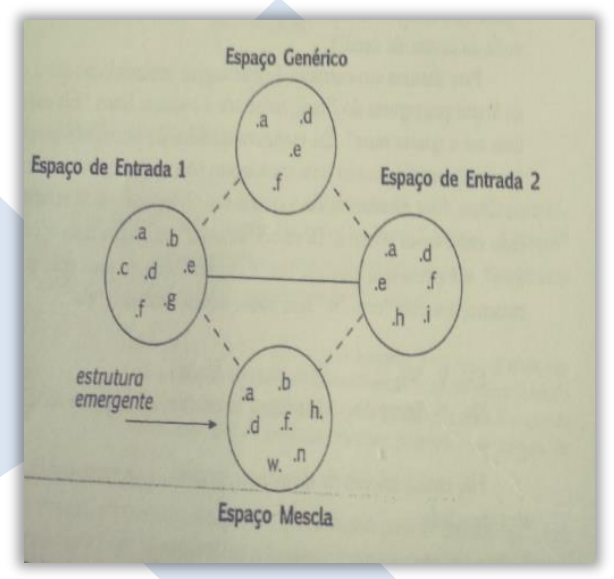

Fonte: Azevedo (2010, p. 92)

Observamos que o diagrama é igual ao anterior, contudo as palavras estão apresentadas em Língua Portuguesa.

A respeito do uso dos diagramas da Teoria da Mesclagem de Fauconnier e Turner nas análises de trechos de discursos, ou categorias maiores, Azevedo (2010, p. 92) afirma que:

Esses diagramas propõem que haja domínios-fontes, ou seja, espaços de entrada (inputs), num mínimo de dois, com suas estruturas informacionais próprias, provendo elementos a serem selecionados para projeção e composição de nova estrutura integrada no espaço mescla, resultante de processos imaginativos. $\mathrm{O}$ espaço genérico do diagrama, que nem sempre aparece representado, informa que as estruturas dos espaços de entrada têm alguma analogia entre si e esses elementos comuns são projetados ao espaço genérico, estruturandoo. Todo o conjunto forma uma rede de espaços mentais, vista como uma rede de integração conceptual. (AZEVEDO, 2010, p. 92). 
É importante salientar também que em meio às análises na integração conceptual, o que será exposto nos diagramas serão informações referentes às nossas experiências do nosso cotidiano, conhecimento de mundo, memórias a longo prazo e também novas experiências, ressaltando também que o contexto social em que estamos inseridos, é um aspecto de extrema relevância, visto que, a partir desse contexto é que acionamos os frames, resposta de toda essa "bagagem" carregada ao longo de nossas vivências.

A seguir apresentamos duas propagandas com suas respectivas análises.

Figura 5 - Anúncio do energético Red Bull.

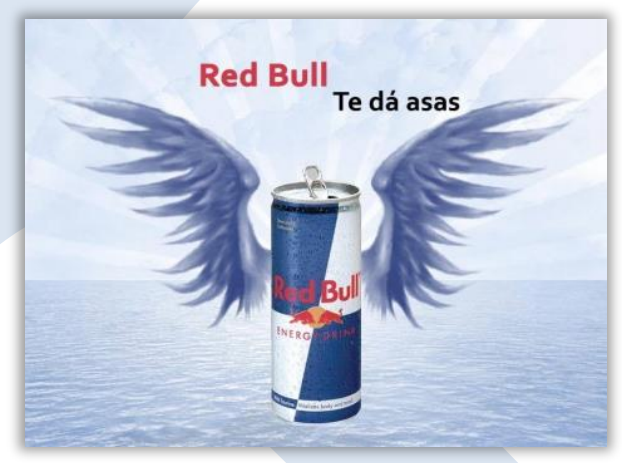

Disponível em: https:/ www.google.com.br/search?biw $=1366 \&$ bih $=613 \&$ tbm $=$ isch\&sa=1\&ei= QVqMWraiEYL_zgKToryQAw\&q=propagandas+dA+BEBIDA+RED+BULL Acesso em: 15 abr. 2018 
Esquema 1: Análise da figura 5

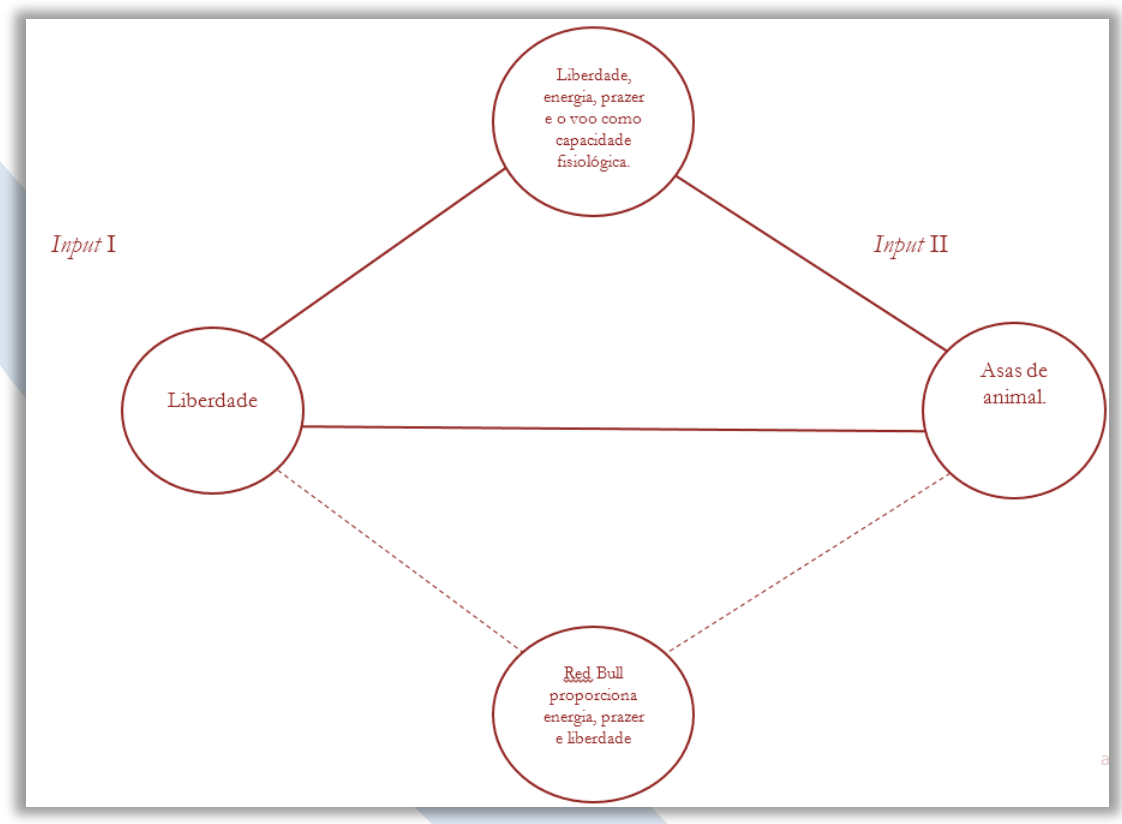

Fonte: Esquema feito pela autora, baseado em Fauconnier e Turner (1999)

A partir do momento em que o leitor visualiza a propaganda, o seu sistema cognitivo identifica a marca do produto como o nome que a bebida está sendo apresentada e ao mesmo tempo tem a ideia de que ao tomar essa bebida, estará recebendo "asas para voar". Essas duas entradas ou inputs se mesclam, se misturam na mente, de modo que a ideia de asas para voar remete a uma interpretação de liberdade, de sensação de êxtase, de energia que essa bebida pode provocar ao consumidor.

A mescla inclui a questão de que a bebida Red Bull proporciona energia, prazer e a enorme sensação de liberdade. A propaganda se apropria da imagem criativa das asas atreladas à bebida, proporcionando uma sensação positiva e eficiente do produto anunciado.

Em nenhum momento, a propaganda do produto informa sobre problemas possíveis de se propagar, a partir do consumo do energético, dentre eles a dependência. A intenção da propaganda é unicamente seduzir o máximo de adeptos à compra da bebida. 
Toda a produção de desenho, metáfora no enunciado almeja à venda. Mesmo que o produto possui substâncias responsáveis por prejuízos à saúde de quem o consumir, a propaganda não tem nenhum interesse em divulgar esse tipo de informação que, por sua vez, faria o consumidor refletir nas consequências do uso, antes de adquirir.

Podemos concluir que a propaganda não está preocupada com os aspectos negativos que o seu produto pode causar ao consumidor. O seu trabalho é ser cada vez mais criativo, visando à maior conquista de consumidores e uma maior rentabilização rentabilidade financeira. As indústrias geram a cada dia mais adeptos ao consumismo e nunca, ou quase nunca, mencionam os fatores prejudiciais ao consumidor.

No que diz respeito a alertar sobre malefícios do produto ao consumidor, podemos destacar as propagandas de cigarros, que por lei do Ministério da Saúde, adverte que tal produto faz mal à saúde e nas propagandas de bebidas alcóolicas menciona sobre beber com moderação. Contudo, são alertas muito rápidos, não enfatizando assim o lado negativo do produto anunciado.

A seguir apresentaremos a anúncio publicitário do produto de limpeza da marca Bom Bril.

Figura 6: Anúncio de produto de limpeza Bom Bril.

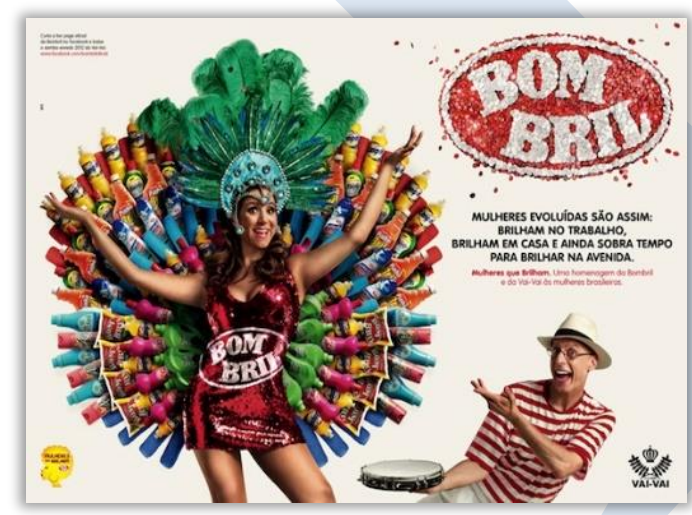

Disponível em: < http://propmark.com.br/static/upload/legacy /thumbs/2014/bombril-carnaval.jpg> Acesso em 15 de abr. 2018

Esquema 2: Análise da figura 6 


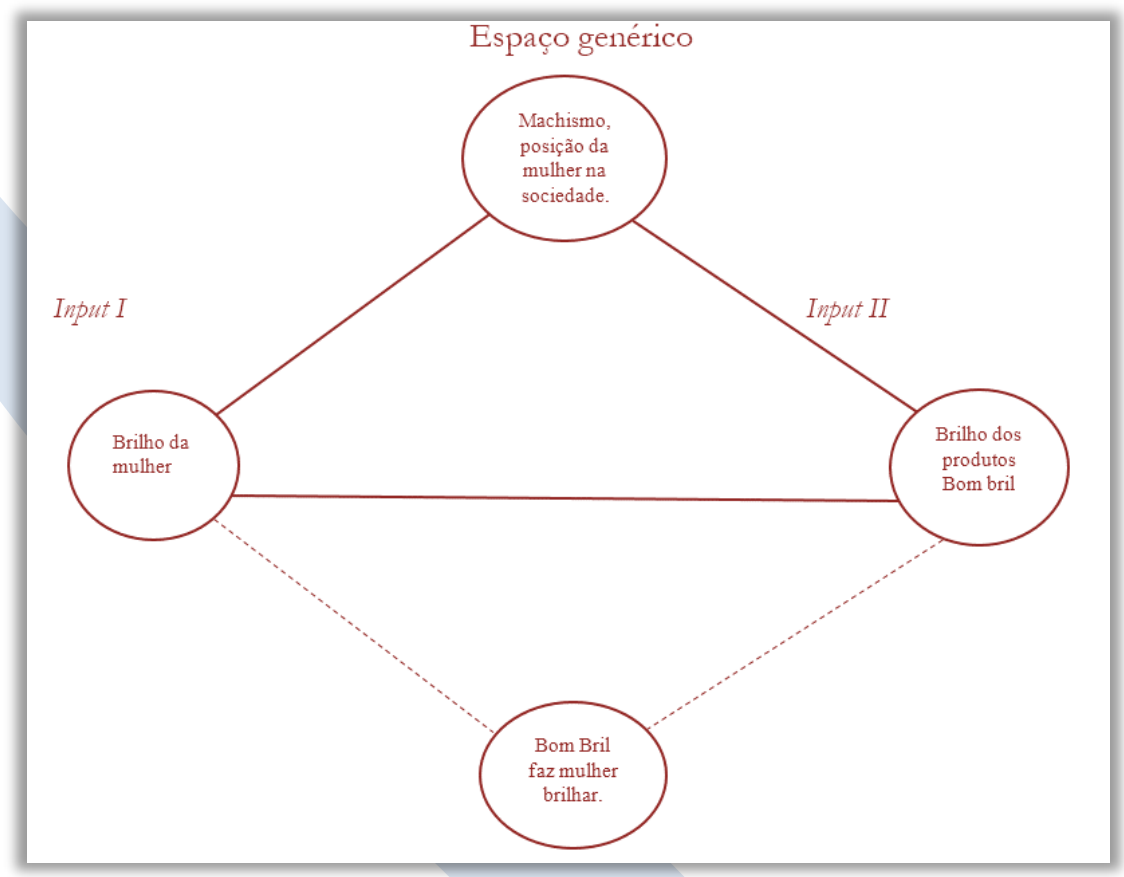

Fonte: Esquema feito pela autora, baseado em Fauconnier e Turner (1999)

O espaço genérico deste anúncio, inclui aspectos mais abstratos que se referem às questões dos papéis da mulher na sociedade machista que retrata a mulher como "dona de casa", "doméstica" que deve fazer a limpeza de casa. Eis o motivo do enunciado revelar a questão do brilho que ela deixa nas coisas de casa com o produto propagado da marca Bom Bril.

A metáfora do "brilho" também se associa à presença da mulher no Carnaval, ela "brilha" também na avenida; ou seja, tem tempo para os afazeres domésticos e também para a festa na avenida. O enunciado expressa através da metáfora do brilho a "multifuncionalidade" da mulher. A sua capacidade de estar presente em contextos diferentes e realmente surpreender, fazer bem feito, seja o que for e aonde for. Relaciona também a questão do tempo da mulher moderna. Ela exerce, cumprindo as suas responsabilidades do lar e 
não abre mão do seu tempo de curtir a festa do Carnaval, atribuindo a essa atitude como evolução: "mulher evoluída". De certo a posição da mulher anteriormente era apenas de cumprir os deveres do lar. Com a "emancipação" de mudanças de valores relacionados a ela, houve de fato uma certa "evolução", embora os "papéis domésticos” ainda permanecem atribuídos à mulher.

Dentro da teoria de Modelos Cognitivos Lakkof (1987) apresenta-nos o caso do uso do estereótipo "dona de casa" para representar a categoria "mãe”, ou seja, quando se entende "dona de casa" como representante prototípica da categoria "mãe", essa categoria conta com diversos modelos, tais como: madrasta, mãe biológica, mãe adotiva, mãe de leite etc. enfim, diversos submodelos que constituem uma rede conceitual, da qual o sujeito elege o seu modelo prototípico, ou seja, aquele que, para ele (sujeito), mais representa a categoria.

A partir das considerações de Lakkof, podemos acrescentar, no que diz respeito à propaganda da Bom Bril, que o enunciado reforça este "lugar" da mulher, como posição de sujeito qualificada como "doméstica”, “do lar”, aquela que tem a função de exercer tarefas da casa, ainda que o anúncio apresenta um outro lado de exercício dela, que é a participação "brilhante" no Carnaval. A imagem da mulher sustentando os produtos de limpeza Bom Bril, emite nas entrelinhas que ela é a portadora desses materiais de limpeza; como se isso fosse produzido diretamente para ela.

Podemos perceber que os estereótipos em relação à mulher estão em continuidade em nossa sociedade. Valores machistas permanecem em destaque. Quando no enunciado afirma que as mulheres são evoluídas, ao "brilhar" na casa e na avenida, fica evidente que houve uma "evolução" comportamental. Ou seja, agora ela pode fazer as tarefas domésticas e depois vai curtir na avenida. Portanto, parece que a mulher não "evoluída" não tem essa atitude. Cumpre os seus deveres do lar e mais nada.

Portanto, o que presenciamos neste anúncio publicitário é uma mensagem engendrada de valores marcados por atribuições machistas representados pelo enunciado escrito 
e também pela imagem, que embora metonímica, carrega em si o valor metafórico do "brilho". Essa metáfora "brilho" refere à qualidade da mulher em seus serviços domésticos e na sua presença no carnaval, na avenida.

Assim, os sentidos da propaganda publicitária são construídos tanto na produção quanto na recepção dos enunciados, frutos da interação entre os sujeitos através da relação forma-sentido, como vemos na propaganda da Bom Bril em que a forma, o modo como a encenação é apresentada dialoga com a intencionalidade de quem a produziu. Essas instâncias enunciativas funcionam com base em intencionalidades, porque tanto aquele que produz quanto aquele que interpreta o fazem com alguma intenção.

\section{Considerações finais}

À luz da Linguística Cognitiva podemos concluir que a metáfora é um fenômeno cognitivo presente em todas as línguas humanas e se pararmos para observar os nossos diálogos cotidianos percebemos que em nenhum momento premeditamos uma formulação metafórica em nossos discursos orais. A metáfora acontece naturalmente, espontaneamente, uma vez que nosso sistema cognitivo linguístico é metafórico.

Vimos a importância dos aspectos culturais presentes na apropriação de metáforas e nos frames. O nosso cognitivo anda de mãos dadas com os as influências culturais que fazem parte das nossas convivências linguísticas. Os frames representam as memórias vivenciadas ao longo da vida, proporcionando então as interpretações e compreensões metafóricas.

Nos anúncios publicitários exemplificados pudemos destacar a presença da metáfora marcante, tanto em seus enunciados, quanto em suas imagens representadas. Uma vez que nosso sistema linguístico cognitivo é metafórico, é evidente que as metáforas vão marcar a sua presença não apenas em textos poéticos, como é comum nos conceitos gramaticais de Figuras de Linguagem, mas também em outros contextos linguísticos, pelos quais nos apropriamos. 
Percebemos a presença da metáfora em propagandas e observamos que as expressões metafóricas possuem uma eficácia em suas representações abstratas, visto que há uma força na emoção quando o denotativo é expresso por uma conotação. Muitos enunciados e imagens criativas são capazes de iludir e persuadir o consumidor a comprar produtos que são anunciados, de modo que esse mecanismo é de sedução para o receptor dessas mensagens.

Cabe-nos refletir sobre os elementos envolvidos nas propagandas que nos cercam, a partir da fantasia dos seus aspectos constitutivos que, geralmente, visam a despertar desejo de aquisição do produto, em um potencial consumidor.

Um dos questionamentos que podem ser feitos é, se realmente, ao adquirir ou consumir este ou aquele produto, a pessoa desfrutará do que propõe o slogan. Por outro lado, frequentemente, precisamos utilizar ou consumir determinados produtos. No momento da escolha dessa ou daquela marca, diante de tantas seduções provocadas pelas estratégias de imagens e enunciados metafóricos em diversos tipos de propagandas, compete-nos refletir sobre que fatores levaremos em conta para fazermos nossa opção de maneira racional e consciente, não levados por possíveis fantasias a que as metáforas possam despertar em nós.

\title{
METAPHORS IN ADVERTISING ANNOUNCEMENTS: AN ANALYSIS THROUGH COGNITIVE LANGUAGE
}

\begin{abstract}
The society is surrounded by advertisements, broadcast through TV, magazines, newspapers, the Internet and other media. Usually the use of figures of thought in these ads, especially of metaphor. This fact motivated us to analyze some of these figures used in commercials involving drinks and cleaning products. Cognitive Linguistics has some theories regarding the approach of metaphors, so it was convenient to opt for one of them to serve as a support for the analysis of the advertisements selected for this contribution. So we chose Fauconnier and Turner's Integration Theory. Advertising is a vehicle that exerts a great influence on people, seducing them with their imagery and creative utterances, in order to persuade the consumer, who is often "entangled" with colors, words and metaphorical images, and in many circumstances, people act, driven by compulsion and end up eventually acquiring goods without having a real need for them. Thus, we point out some clues that can help people in the process of analyzing commercial ads, which can favor them in the process of their choices, amid the seductive power of advertisements.
\end{abstract}

KEYWORDS: Cognitive linguistics; Metaphor; Advertising. 


\section{REFERÊNCIAS}

AZEVEDO, A. M. T. de. Uma breve apresentação da teoria dos espaços mentais e da teoria da mesclagem. Belo Horizonte: Faculdade de Letras da UFMG, 2010.

FAUCONNIER, G. Mappings in thought and language. Cambridge: Cambridge University Press, 1999.

FAUCONNIER, G. \& TURNER, M. Rethinking Metaphor. In: GIBBS, R. W. Jr. (ed.). The Cambridge handbook of metaphor and thought. Cambridge: Cambridge University Press, 2008. p. 53-66. The Way We Think. New York: Basic Books, 2003.

FERRARI, L. Introdução à linguística cognitiva. Editora Contexto; São Paulo- SP, 2011.

FILLMORE, Charles. Frame Semantics. In: The linguistic society of Korea (Ed.). Linguistics in the morning calm. Seoul: Hanshin, 1985.

KÖVECSES, Zoltán., Emotion concepts. Berlin and New York: SpringerVerlag, 2003.

KÖVECSES, Z. Language, mind and culture: a practical introduction. Oxford University Press, 2006.

LAKOFF, G.; JOHNSON. Philosophy in the flesh: the embodied mind and its challenge to western thought. New York: Basic Books, 1999

LAKOFF, G. e JOHNSON, M. Metáforas da vida cotidiana. (Coordenação da Tradução Mara Sophia Zanotto) Campinas, SP: Mercados de Letras; São Paulo : EDUC, 2002.

LAKOFF, G. Women, fire, and dangerous things: what categories reveal about the mind. Chicago: The University of Chicago Press, 1987.

Recebido em: 30/07/2018.

Aprovado em: 14/10/2018. 